\title{
Occlusion rates of intracranial aneurysms treated with the Pipeline embolization device: the role of branches arising from the sac
}

\author{
Felipe Padovani Trivelato, MD, ${ }^{1}$ Marco Túlio Salles Rezende, MD, ${ }^{1}$ Alexandre Cordeiro Ulhôa, MD, \\ Luis Henrique de Castro-Afonso, MD, PhD, ${ }^{2}$ Guilherme Seizem Nakiri, MD, ${ }^{2}$ and \\ Daniel Giansante Abud, PhD²
}

'Division of Interventional Neuroradiology, Felício Rocho Hospital, Belo Horizonte, Minas Gerais; and 2Division of Interventional Neuroradiology, Hospital das Clínicas, Medical School, University of São Paulo, Ribeirão Preto, São Paulo, Brazil

\begin{abstract}
OBJECTIVE The aim of this study was to compare the clinical and angiographic outcomes of intracranial aneurysms with and without branches arising from the sac after Pipeline embolization device (PED) treatment.

METHODS This retrospective 2-center comparative study included 116 patients with 157 aneurysms that were treated with PEDs. Aneurysms were divided into 2 groups: one group had branches arising from the sac and the other group did not. Study end points included total aneurysm occlusion assessed by angiography at 6 and 12 months, death or stroke, technical complications, in-stent stenosis, patency of covered branches, and transient ischemia.
\end{abstract}

RESULTS One hundred fifty-one aneurysms (96\%) were located in the internal carotid artery. A branch arising from the sac was observed in 26 aneurysms. Complete occlusion was found in 120 of 156 aneurysms at 6 months (76.92\% [95\% $\mathrm{Cl} 69.71 \%-82.84 \%]$ ) and in 136 of 155 aneurysms at 12 months (87.74\% [95\% Cl 81.28\%-92.27\%]). Total occlusion was more frequently observed in the group without a branch arising from the sac ( $84 \%$ vs $40 \%$ at 6 months, $p<0.001$; $93.10 \%$ vs $60 \%$ at 1 year, $p<0.001)$. There were $4(3.45 \%$ [95\% Cl $1.11 \%-9.12 \%])$ cases of death or major stroke. Amaurosis fugax occurred in 3 patients. One patient experienced worsening of mass effect after treatment. No occlusion of branches arising from the aneurysm was observed. In-stent stenosis greater than $50 \%$ was observed in 1 case.

CONCLUSIONS Aneurysms treated with PEDs are less likely to be totally occluded if they have a branch arising from the sac than are aneurysms without these branches.

https://thejns.org/doi/abs/10.3171/2017.10.JNS172175

KEYWORDS aneurysm; embolization; endovascular; vascular disorders

$\mathrm{S}$ EVERAL studies, including the International Subarachnoid Aneurysm Trial, ${ }^{14}$ the Barrow Ruptured Aneurysm Trial, ${ }^{23}$ and the California unruptured aneurysm database, ${ }^{8}$ have provided strong evidence that endovascular treatment has equipoise with, and in appropriately selected patients may be superior to, neurosurgical clipping. ${ }^{4}$ Therefore, over time, coiling has become the first-line treatment for ruptured and unruptured aneurysms. ${ }^{6,8,14,23,26}$

However, a limitation of endovascular treatment rapidly became obvious in large to giant, wide-necked, dissecting, and fusiform aneurysms. ${ }^{3,19}$ In such scenarios, the development of flow diverter devices was groundbreaking in the treatment of intracranial aneurysms. Their safety and efficacy have been demonstrated in several trials. ${ }^{10,13}$ Therefore, an increasing number of aneurysms are being managed using this approach. It is estimated that $47 \%$ of aneurysms (and 90\% of internal carotid artery aneurysms) would likely be amenable to treatment with flow diverters. ${ }^{4}$

Although the Pipeline embolization device (PED, Medtronic) is highly efficient in promoting durable aneurysm occlusion, close to one-fifth of the intracranial aneurysms treated with the PED will not become occluded, and information on predictors of flow diverter failure is lacking. ${ }^{17,21,25}$

ABBREVIATIONS AChA = anterior choroidal artery; mRS = modified Rankin Scale; NIHSS = National Institutes of Health Stroke Scale; PCoA = posterior communicating artery; PED = Pipeline embolization device.

SUBMITTED August 30, 2017. ACCEPTED October 7, 2017.

INCLUDE WHEN CITING Published online April 6, 2018; DOI: 10.3171/2017.10.JNS172175. 
Small, noncomparative studies suggest that the incorporation of a branch vessel into the aneurysm fundus could potentially contribute to unsuccessful treatment with flow diverters; $;, 21,25$ however, the analyses of these studies have very weak statistical power.

We evaluated a consecutive series of intracranial aneurysms treated with PEDs and compared the occlusion rates between aneurysms harboring branches arising from the sac and those without these branches. Additionally, we tried to identify potential predictors of treatment outcomes for cerebral aneurysms, with a particular focus on the anatomical characteristics related to the failure of flow diverters.

\section{Methods \\ Study Design}

This was an observational, retrospective, 2-center study conducted in accordance with the Declaration of Helsinki and the Declaration of Good Clinical Practice and was approved by the ethics review board of both institutions. Signed informed consent was obtained.

Inclusion criteria were as follows: 1) saccular or fusiform intracranial aneurysms; 2) untreated aneurysms or recurrent aneurysms after previous treatment; 3) unruptured aneurysms; 4) sidewall aneurysms; and 5) aneurysms treated with the PED. Exclusion criteria were as follows: 1) ruptured aneurysms; 2) bifurcation aneurysms; and 3) presence of a preexisting laser-cut stent. Between November 2011 and June 2016, 157 unruptured intracranial aneurysms in 116 patients were treated with flow diverters at 2 centers (Felício Rocho Hospital and University of São Paulo).

\section{Primary End Point}

The primary outcome of the study was total occlusion of the aneurysm after treatment with PEDs, assessed by catheter angiography at 6 months and 12 months. Complete occlusion was defined as complete aneurysm obliteration, including the neck.

\section{Secondary End Points}

The secondary safety outcome was death or stroke within 1 year after treatment. Technical complications, instent stenosis, patency of covered branches, and transient ischemia, including retinal ischemia, were also evaluated.

\section{Endovascular Procedure}

Patients were asked to take clopidogrel $(75 \mathrm{mg})$ and aspirin $(100 \mathrm{mg})$ for 5 days prior to the treatment, and for 6 months afterward. At least $100 \mathrm{mg}$ daily oral aspirin was then given for another 6 months. No antiplatelet function testing was used. Heparin was given in an initial bolus of $5000 \mathrm{U}$ and adjusted to achieve and maintain an activated clotting time between 250 and 300 seconds. Heparin reversal was not performed at the end of the procedure. The PED was the only flow diverter used.

\section{Data Collection}

All data from both centers were collected prospec- tively. Preoperative data included age, sex, clinical presentation, modified Rankin Scale (mRS) score, National Institutes of Health Stroke Scale (NIHSS) score, aneurysm location, position of the aneurysm in relation to the angulation of the parent artery, previous treatment, aneurysm size (diameter, neck, and dome/neck ratio), and the presence of an artery arising from the sac. Operative data included treated aneurysms, the size of the flow diverter, balloon angioplasty, technical complications, thromboembolic complications, and side branches covered by the flow diverter. Postoperative evaluation included immediate occlusion rate, neurological complications, in-stent stenosis, patency of the covered side branches, device migration, $\mathrm{mRS}$ score, NIHSS score, and occlusion rate.

Radiological follow-up included 3 digital subtraction angiography sessions: immediately after the procedure, after 6 months, and after 1 year. Images were analyzed by an independent neuroradiologist with experience in flow diverter treatment. Clinical follow-up included a neurological consultation with an independent neurologist before the procedure and then 30 days, 6 months, and 1 year after the procedure.

\section{Statistical Analysis}

Aneurysms were divided into 2 groups: those with a branch arising from the aneurysm sac and those without a branch arising from the sac. The results in both groups were compared.

Continuous variables are presented as the mean \pm SD and range, and categorical variables are presented as numbers and percentages. In descriptive analyses, comparison between groups (with and without branches arising from the aneurysms) was performed using the Mann-Whitney test for categorical variables and Fisher's exact test for continuous variables.

Regarding the comparison between groups, the generalized equations estimating method was used. Marginal logistic regression was performed to assess the occlusion rates at 6 months and 1 year after treatment for both groups.

Additionally, to evaluate the correlation between the 7 variables (presence of a branch arising from the sac, age, number of flow diverters deployed, aneurysm location, aneurysm diameter, neck size, and dome/neck ratio) and 3 outcomes (total occlusion, mRS score $<3$, and complications), the generalized equations estimating method was used and was applied to the univariate and multivariate marginal logistic regression models. $\mathrm{R}$ version 3.2.4 software (Institute for Statistics and Mathematics) was used; $p$ $<0.05$ was considered to indicate a statistically significant difference.

\section{Results}

\section{Patient Demographics}

Among 116 patients, $71(61.2 \%)$ were asymptomatic, $32(27.6 \%)$ presented with headache, and $13(11.2 \%)$ presented with symptoms due to mass effect. Sixteen (10.2\%) aneurysms had been treated previously, 4 with clipping and 12 with coil treatment. There were 104 female patients (89.7\%) and 12 male patients, with a mean age of $51.9 \pm$ 
12.8 years (median 54 years, range $12-79$ years). The mRS score was 0 in 99 patients, 1 in 8 patients, 2 in 6 patients, 3 in 2 patients, and 5 in 1 patient before PED treatment.

\section{Aneurysm Characteristics}

There were $150(95.5 \%)$ saccular aneurysms and 7 (4.5\%) fusiform aneurysms. Nine aneurysms were located in the posterior circulation. A branch arising from the sac was observed in 26 aneurysms: the ophthalmic artery in 16 , the posterior communicating artery $(\mathrm{PCoA})$ in 4 , the anterior choroidal artery (AChA) in 3, the anterior inferior cerebellar artery in 1, the posterior inferior cerebellar artery in 1, and a lenticulostriate artery from the middle cerebral artery in 1 . In 131 aneurysms, branches were not present. The characteristics for both groups are shown in Table 1 . A statistically significant difference between the groups was found for the dome/neck ratio. In both groups, the most frequent localization was paraophthalmic. In the group without branches, the second most frequent localization was cavernous, while in the group with branches, the second most common localization was in the communicating segment.

\section{Treatment Characteristics}

The procedure was successfully accomplished in all patients. Two patients underwent 2 procedures because of bilateral aneurysms. A total of 152 aneurysms were treated with 1 PED, and 5 aneurysms were treated with 2 PEDs (Table 2). Balloon angioplasty was used in 30 of 118 procedures to achieve good wall apposition. Concomitant coil placement at the time of the PED procedure was performed in 9 aneurysms.

\section{Primary End Point}

Complete occlusion was observed in 120 of 156 aneurysms at 6 months (76.92\% [95\% CI 69.71\%-82.84\%]) and in 136 of 155 aneurysms at 12 months $(87.74 \%$ [95\% CI $81.28 \%-92.27 \%]$ ) (Table 3). Two patients were lost to follow-up. Total angiographic occlusion was more frequently observed in aneurysms without a branch arising from the sac (Figs. 1 and 2). After 1 year, the branches associated with occlusion failure were the ophthalmic artery in 7 cases, the PCoA in 1 case, and the AChA in 1 case. Even considering total occlusion and near-total occlusion as a unique group, the difference between groups remained statistically significant. Excluding the cases in which the PCoA was the branch arising from the sac, the results are the same.

Univariate analysis demonstrated that total occlusion was associated with the absence of branches arising from the aneurysm (Table 3). Multivariate analysis confirmed these findings and revealed that the diameter of the an-

TABLE 1. Characteristics of groups

\begin{tabular}{|c|c|c|c|c|}
\hline \multirow[b]{2}{*}{ Variable } & \multirow[b]{2}{*}{ Overall } & \multicolumn{2}{|c|}{ Group } & \multirow[b]{2}{*}{ p Value } \\
\hline & & w/o Branch $(n=131)$ & w/ Branch $(n=26)$ & \\
\hline Sex ${ }^{*}$ & & & & 0.060 \\
\hline Female & $104(89.66)$ & $86(92.50)$ & $18(78.30)$ & \\
\hline Male & $12(10.34)$ & $7(7.50)$ & $5(21.70)$ & \\
\hline Localization & & & & 0.644 \\
\hline Anterior & $148(94.27)$ & $124(94.70)$ & $24(92.30)$ & \\
\hline Posterior & $9(5.73)$ & $7(5.30)$ & $2(7.70)$ & \\
\hline Topography & & & & 0.010 \\
\hline Cavernous & $25(15.92)$ & $25(19.08)$ & $0(0.00)$ & \\
\hline Paraophthalmic & $96(61.15)$ & $80(61.07)$ & $16(61.54)$ & \\
\hline Communicating & $21(13.38)$ & $14(10.68)$ & $7(26.92)$ & \\
\hline Other & $15(9.55)$ & $12(11.45)$ & $3(11.54)$ & \\
\hline Angulation & & & & 0.105 \\
\hline Straight & $29(18.74)$ & $22(16.80)$ & $7(26.90)$ & \\
\hline Convexity & $112(71.34)$ & $93(71.00)$ & $19(73.10)$ & \\
\hline Concavity & $16(10.19)$ & $16(12.20)$ & $0(0)$ & \\
\hline Side & & & & 0.118 \\
\hline $\mathrm{Rt}$ & $66(42.86)$ & $52(40.00)$ & $14(58.30)$ & \\
\hline $\mathrm{Lt}$ & $88(57.14)$ & $78(60.00)$ & $10(41.70)$ & \\
\hline Mean age in yrs & $51.89 \pm 12.80$ & $52.50 \pm 1.32$ & $49.44 \pm 2.69$ & 0.346 \\
\hline Mean diameter in $\mathrm{mm}$ & $7.97 \pm 6.06$ & $8.04 \pm 0.53$ & $7.64 \pm 1.26$ & 0.897 \\
\hline Mean neck size in $\mathrm{mm}$ & $4.87 \pm 3.06$ & $4.71 \pm 0.24$ & $5.67 \pm 0.82$ & 0.218 \\
\hline Mean dome/neck ratio & $1.60 \pm 0.74$ & $1.67 \pm 0.07$ & $1.29 \pm 0.07$ & 0.019 \\
\hline Stroke/death & $2 / 2(3.45)$ & $2 / 1(2.59)$ & $0 / 1(0.86)$ & $>0.99$ \\
\hline
\end{tabular}

Values are presented as the number of aneurysms (\%) unless stated otherwise. Mean values are presented as the mean \pm SD.

* Percentages are based on the number of patients. 
TABLE 2. Treatment characteristics

\begin{tabular}{ccccc}
\hline \multirow{2}{*}{ Variable } & Overall & w/o Branch & w/ Branch & \multirow{2}{c}{$\begin{array}{c}\text { Group } \\
\text { Value }\end{array}$} \\
\cline { 3 - 4 } No. of PEDs/aneurysm & & & & 0.032 \\
\hline 1 & $152(96.82)$ & $129(98.50)$ & $23(88.50)$ & \\
\hline$>1$ & $5(3.18)$ & $2(1.50)$ & $3(11.50)$ & \\
\hline Balloon angioplasty & & & & 0.803 \\
\hline No & $88(74.58)$ & $67(72.83)$ & $20(76.92)$ & \\
\hline Yes & $30(25.42)$ & $25(27.17)$ & $6(23.07)$ & \\
\hline Coils also placed & & & & $>0.99$ \\
\hline No & $148(94.27)$ & $123(93.90)$ & $25(96.20)$ & \\
\hline Yes & $9(5.73)$ & $8(6.10)$ & $1(3.80)$ & \\
\hline
\end{tabular}

Values are presented as the number of aneurysms (\%) unless stated otherwise. * In 118 procedures.

eurysm impacted negatively on the total occlusion rate (Table 4).

\section{Secondary End Points}

Four (3.45\% [95\% CI 1.11\%-9.12\%]) deaths or major stroke occurred in 1 year. There were 2 major strokes: embolic ischemia to the occipital cortex in a patient who underwent basilar artery aneurysm treatment and ischemia of a perforating vessel in a patient who underwent treatment of an aneurysm at the $\mathbf{M}_{1}$ segment. Two deaths occurred: one patient had a giant fusiform basilar aneurysm, and the other had a partially thrombosed basilar aneurysm. No intracranial bleeding from an aneurysm or bleeding not related to the aneurysm occurred. Amaurosis fugax occurred in 3 patients during the 1st year. One patient harboring a giant, cavernous aneurysm experienced transitory worsening of mass effect after treatment. No occlusion of branches arising from the aneurysm was observed. In-stent stenosis greater than $50 \%$ was observed in 1 case.

We observed 1 thrombotic complication inside the flow diverter, which was treated with abciximab without ischemic consequences. In 2 patients harboring internal carotid artery aneurysms, dissection occurred during the navigation of the distal access catheter, but the patients were asymptomatic.

\section{Discussion}

The PED has emerged as an important tool for the treatment of complex intracranial aneurysms. It is the most widely used flow diverter in interventional neuroradiology. ${ }^{2,4,5,9,10,13,15,16,24}$ The device gained FDA approval for use in adults with giant and large aneurysms between the petrous and superior hypophyseal segments of the internal carotid artery, but smaller and morphologically less complex aneurysms are increasingly treated with PEDs. ${ }^{1,2}$ Thus, in an increasing number of cerebrovascular centers, the PED has become a first-line option for unruptured sidewall cerebral aneurysms. ${ }^{4}$

Compared with traditional embolization techniques, flow diverters have proved to be more efficient and at least as safe as traditional embolization techniques. ${ }^{1-3,5}$ Endoluminal flow diversion has been shown in clinical studies to achieve high rates of aneurysm occlusion. $3,4,6,13,15,16,24,26$

A pooled analysis of 3 large studies revealed that complete occlusion rates after PED treatment were $75.0 \%$, $85.5 \%$, and $93.4 \%$ at 6 months, 1 year, and 3 years, respectively. However, approximately $10 \%-20 \%$ of treated aneurysms will not be occluded. ${ }^{10}$ Moreover, current knowledge about flow diversion does not allow for reliable predictions about occlusion probability in a given aneurysm.

Several factors and mechanisms have been described

TABLE 3. Angiographic outcome

\begin{tabular}{|c|c|c|c|c|c|}
\hline \multirow[b]{2}{*}{ Variable } & \multirow[b]{2}{*}{ Overall } & \multicolumn{3}{|c|}{ Group } & \multirow[b]{2}{*}{ p Value } \\
\hline & & w/o Branch & & nch & \\
\hline & & & & & \\
\hline Complete occlusion & $120(76.92)$ & $110(84.00)$ & 10 & 40.00 & \\
\hline Residual filling & $36(23.08)$ & $21(16.00)$ & 15 & 60.00 & \\
\hline $12 \mathrm{mos}$ & & & & & $<0.001$ \\
\hline Complete occlusion & $136(87.74)$ & $121(93.10)$ & 15 & 60.00 & \\
\hline Residual filling & $19(12.26)$ & $9(6.90)$ & 10 & 40.00 & \\
\hline 12 mos & & & & & 0.003 \\
\hline Total/near-total occlusion & 144 (92.91) & $125(96.20)$ & 19 & 76.00 & \\
\hline Partial occlusion/no occlusion & $11(7.09)$ & $5(3.80)$ & 6 & 24.00 & \\
\hline $12 \mathrm{mos}$ & & & & & $<0.001$ \\
\hline Total occlusion & 133 & 121 & $13^{*}$ & & \\
\hline Residual filling & 20 & 9 & $8^{*}$ & & \\
\hline Groupt & OR $(95 \% \mathrm{Cl})$ & & & & $<0.001$ \\
\hline w/ branch & Ref & & & & \\
\hline w/o branch & $5.35(2.12-13.53)$ & & & & \\
\hline
\end{tabular}



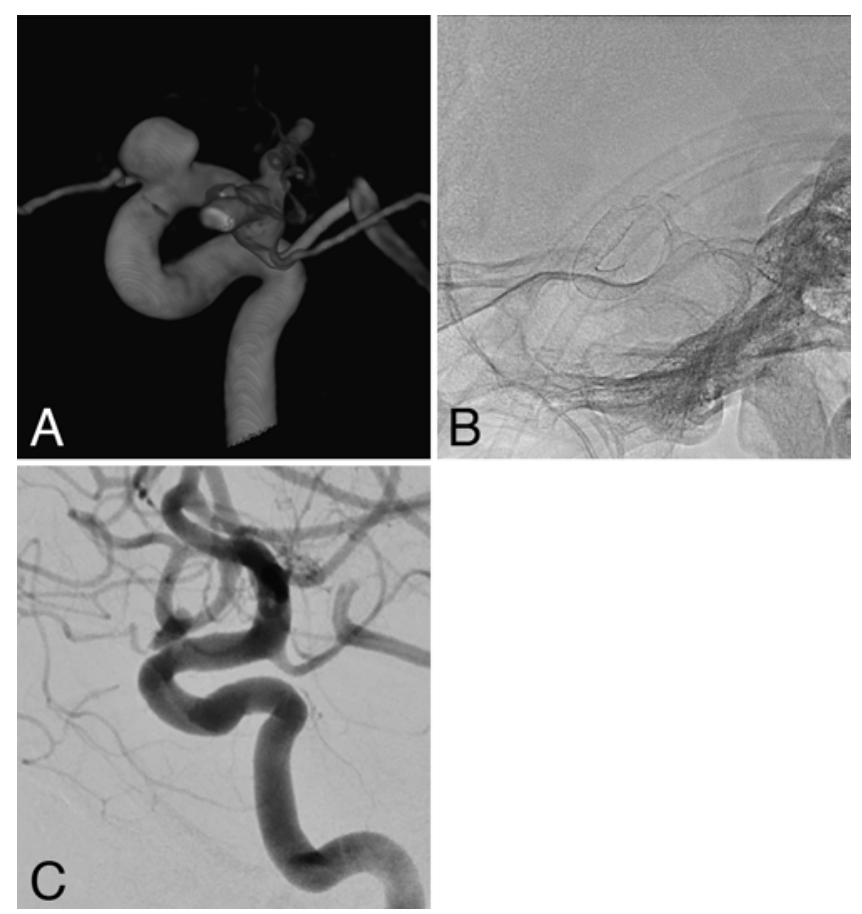

FIG. 1. Incidental finding in a 67-year-old woman. A: Lateral 3D catheter angiogram showing a wide-necked internal carotid artery aneurysm. The ophthalmic artery arises from the sac. B: Fluoroscopic image demonstrating the PED deployed. C: Control angiogram revealing partial occlusion of the aneurysm with a patent ophthalmic artery 1 year after treatment.

and are potentially responsible for failed occlusion. Predictors of treatment failure include fusiform aneurysm morphology, decreasing dome/neck ratio, the presence of a preexisting laser-cut stent, device malposition, inadequate coverage of the aneurysm neck, and variable porosity of the device in curved vessels. ${ }^{20-22}$ In addition to those predictors, the incorporation of a branch vessel into the aneurysm fundus has repeatedly been reported as a potential contributing factor to treatment failure. .11,12,21 $^{2}$

In 2015, Kan et al. ${ }^{11}$ reported the cases of 4 patients with fetal PCoA aneurysms who underwent treatment with the PED. Aneurysm occlusion failed in all patients, despite the addition of coils in 3 of the cases. The authors emphasized that a fetal posterior cerebral artery is an end vessel with no distal collaterals, and the demand of this large vessel will maintain flow and patency even after placement of a flow diverter because of the pressure gradient across the ostium. They concluded that flow diversion for fetal PCoA aneurysms is ineffective. Tsang et al. ${ }^{25}$ also found that this type of aneurysm is associated with a particularly poor occlusion rate. In our series, 1 patient harboring an aneurysm with a fetal PCoA arising from the sac was treated. We decided to place coils in addition to the PED. Control angiography 6 months after treatment demonstrated complete occlusion.

Despite the presence of potential anastomosis with the external carotid artery, the same behavior (i.e., treatment of aneurysms was ineffective) was observed with aneurysms in the ophthalmic artery arising from the sac. The
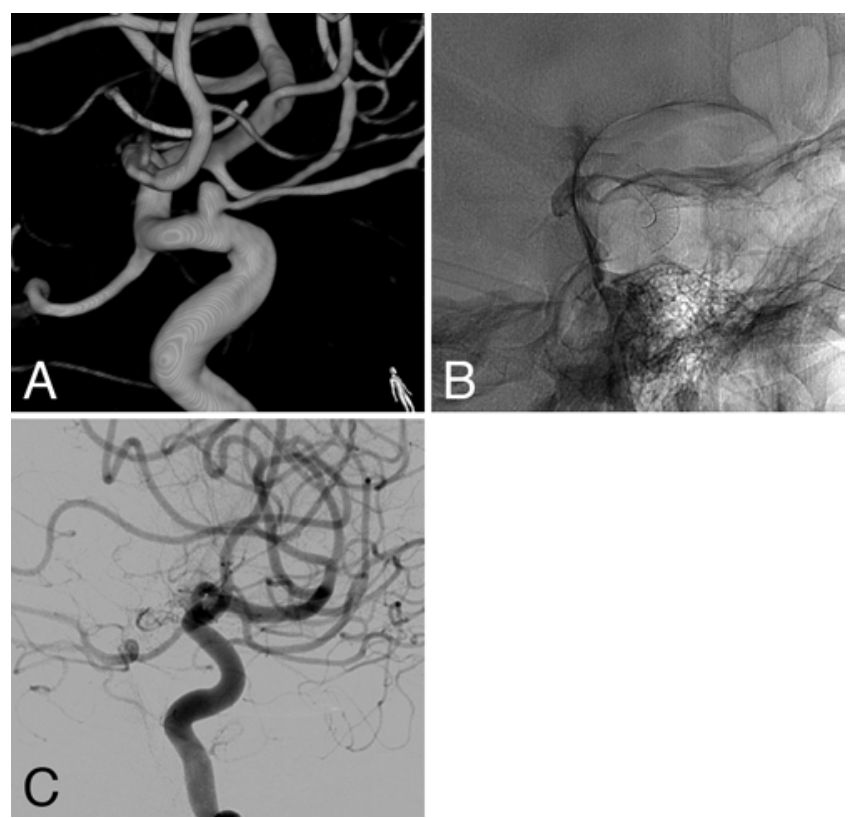

FIG. 2. A 25-year-old woman with a family history of subarachnoid hemorrhage. A: Oblique digital subtraction angiography image demonstrating a small internal carotid artery aneurysm, with the ophthalmic artery originating from the sac. B: Fluoroscopic image showing the PED implanted. C: Control angiography showing complete occlusion of the aneurysm with a remodeled ophthalmic artery 1 year after treatment.

occlusion rate at the last follow-up (mean 11.5 months) was only $50 \%$.

Shapiro et al. ${ }^{21}$ reported a series of $19(21 \%)$ aneurysms that remained unoccluded at 12 months. The aneurysms were thought to remain due to branch vessel runoff in 7 of these cases (4 ophthalmic arteries and 3 PCoAs arising from the sac).

Additionally, Kan et al..$^{12}$ reported on a cohort of 15 patients with 16 cerebral aneurysms that incorporated an end vessel with no significant collaterals, which were treated with PEDs. The series included 7 PCoA aneurysms, 5 ophthalmic artery aneurysms, 1 superior cerebellar artery aneurysm, 1 anterior inferior cerebellar artery aneurysm,

TABLE 4. Multivariate analysis for total occlusion

\begin{tabular}{cccc}
\hline Variable & OR & $95 \% \mathrm{Cl}$ & $\mathrm{p}$ Value \\
\hline Group & \multicolumn{2}{c}{$<0.001$} \\
\hline w/ branch & Ref & Ref & \\
\hline w/o branch & 7.31 & $2.70-19.75$ \\
\hline Localization & \multicolumn{2}{c}{0.250} \\
\hline Anterior & Ref & Ref & \\
\hline Posterior & 8.44 & $0.30-235.85$ \\
\hline Topography & \multicolumn{2}{c}{ Ref } \\
\hline Communicating & Ref & \\
\hline Cavernous/other & 1.99 & $0.49-8.11$ & 0.340 \\
\hline Paraophthalmic & 0.54 & $0.22-1.36$ & 0.193 \\
\hline Diameter & 0.85 & $0.73-0.99$ & 0.044 \\
\hline
\end{tabular}


and 2 middle cerebral artery aneurysms. None of the aneurysms achieved significant occlusion at the last followup (mean 24 months).

The present series demonstrated a similar result: aneurysms with branches arising from the sac are less likely to totally occlude after 1 year $(60.0 \%$ vs $93.1 \%)$. Considering total and near-total occlusion as a single group, the difference remains statistically significant (76.0\% vs $96.2 \%)$. A PCoA aneurysm treated with a PED can present with residual filling not only because of the pressure gradient toward the aneurysm created by the branch but also theoretically through retrograde filling of the sac via the posterior circulation. However, even after excluding PCoA aneurysms from the analysis, the difference in occlusion rates remains.

The patency of jailed arteries and perforators arising from normal segments covered by flow diverters is theoretically guaranteed by the pressure gradient toward the vessel. These same physiological processes can contribute to persistent filling of the aneurysm when an artery is incorporated into the sac.

Although the 1-year occlusion rate for aneurysms with a branch arising from the sac was low, 88\% (22 of 25) of these aneurysms exhibited partial shrinkage greater than $50 \%$. Angiographic outcomes are surrogate markers for patient outcomes. Moreover, aggressive attempts at complete occlusion may lead to morbidity due to re-treatment. .8,19 $^{18}$ The natural history of residual aneurysms after treatment with flow diverters is still poorly known. To improve occlusion rates, the placement of coils in addition to flow diverters to treat aneurysms with branches arising from the sac must be investigated. Another strategy would be the deployment of multiple overlapping devices. However, Shapiro et al. ${ }^{21}$ reported 7 aneurysms with branches arising from the sac that failed to be occluded, despite the use of an average of 3 PEDs per case. Therefore, the efficacy of using more than one device to improve the occlusion rate should be better studied.

The major strength of this study is that it is the first to compare occlusion rates of aneurysms with and without an artery arising from the sac that were treated with PEDs. A significant number of patients were involved, and only 2 patients were lost to follow-up.

On the other hand, the major limitations are the retrospective design of the study and the relatively short followup period, which may underestimate the efficacy of PEDs in the patients with branches arising from the sac, since one might expect more long-term complete occlusions in this group.

\section{Conclusions}

Intracranial aneurysms treated with PEDs are less likely to be totally occluded after 6 months and 1 year if they have a branch arising from the sac than are aneurysms without those branches.

\section{References}

1. Becske T, Brinjikji W, Potts MB, Kallmes DF, Shapiro M, Moran CJ, et al: Long-term clinical and angiographic outcomes following Pipeline Embolization Device treatment of complex internal carotid artery aneurysms: five-year results of the Pipeline for uncoilable or failed aneurysms trial. Neurosurgery 80:40-48, 2017

2. Becske T, Kallmes DF, Saatci I, McDougall CG, Szikora I, Lanzino G, et al: Pipeline for uncoilable or failed aneurysms: results from a multicenter clinical trial. Radiology 267:858868,2013

3. Becske T, Potts MB, Shapiro M, Kallmes DF, Brinjikji W, Saatci I, et al: Pipeline for uncoilable or failed aneurysms: 3-year follow-up results. J Neurosurg 127:81-88, 2017

4. Brinjikji W, Cloft HJ, Fiorella D, Lanzino G, Kallmes DF: Estimating the proportion of intracranial aneurysms likely to be amenable to treatment with the pipeline embolization device. J Neurointerv Surg 5:45-48, 2013

5. Chalouhi N, Tjoumakaris S, Starke RM, Gonzalez LF, Randazzo C, Hasan D, et al: Comparison of flow diversion and coiling in large unruptured intracranial saccular aneurysms. Stroke 44:2150-2154, 2013

6. Fiorella D, Lylyk P, Szikora I, Kelly ME, Albuquerque FC, McDougall CG, et al: Curative cerebrovascular reconstruction with the Pipeline embolization device: the emergence of definitive endovascular therapy for intracranial aneurysms. J Neurointerv Surg 1:56-65, 2009

7. Griessenauer CJ, Ogilvy CS, Foreman PM, Chua MH, Harrigan MR, Stapleton CJ, et al: Pipeline Embolization Device for small paraophthalmic artery aneurysms with an emphasis on the anatomical relationship of ophthalmic artery origin and aneurysm. J Neurosurg 125:1352-1359, 2016

8. Johnston SC, Zhao S, Dudley RA, Berman MF, Gress DR: Treatment of unruptured cerebral aneurysms in California. Stroke 32:597-605, 2001

9. Kallmes DF, Brinjikji W, Cekirge S, Fiorella D, Hanel RA, Jabbour P, et al: Safety and efficacy of the Pipeline embolization device for treatment of intracranial aneurysms: a pooled analysis of 3 large studies. J Neurosurg 127:775-780, 2017.

10. Kallmes DF, Hanel R, Lopes D, Boccardi E, Bonafé A, Cekirge $S$, et al: International retrospective study of the Pipeline Embolization Device: a multicenter aneurysm treatment study. AJNR Am J Neuroradiol 36:108-115, 2015 (Erratum in AJNR Am J Neuroradiol 36:E39-E40, 2015)

11. Kan P, Duckworth E, Puri A, Velat G, Wakhloo A: Treatment failure of fetal posterior communicating artery aneurysms with the pipeline embolization device. J Neurointerv Surg 8:945-948, 2016

12. Kan P, Srinivasan VM, Mbabuike N, Tawk RG, Ban VS, Welch BG, et al: Aneurysms with persistent patency after treatment with the Pipeline Embolization Device. J Neurosurg 126:1894-1898, 2017

13. Lylyk P, Miranda C, Ceratto R, Ferrario A, Scrivano E, Luna HR, et al: Curative endovascular reconstruction of cerebral aneurysms with the Pipeline embolization device: the Buenos Aires experience. Neurosurgery 64:632-643, N6, 2009

14. Molyneux AJ, Kerr RS, Yu LM, Clarke M, Sneade M, Yarnold JA, et al: International Subarachnoid Aneurysm Trial (ISAT) of neurosurgical clipping versus endovascular coiling in 2143 patients with ruptured intracranial aneurysms: a randomised comparison of effects on survival, dependency, seizures, rebleeding, subgroups, and aneurysm occlusion. Lancet 366:809-817, 2005

15. Nelson PK, Lylyk P, Szikora I, Wetzel SG, Wanke I, Fiorella D: The pipeline embolization device for the intracranial treatment of aneurysms trial. AJNR Am J Neuroradiol 32:34-40, 2011

16. O'Kelly CJ, Spears J, Chow M, Wong J, Boulton M, Weill A, et al: Canadian experience with the pipeline embolization device for repair of unruptured intracranial aneurysms. AJNR Am J Neuroradiol 34:381-387, 2013

17. Ouared R, Larrabide I, Brina O, Bouillot P, Erceg G, Yilmaz $\mathrm{H}$, et al: Computational fluid dynamics analysis of flow re- 
duction induced by flow-diverting stents in intracranial aneurysms: a patient-unspecific hemodynamics change perspective. J Neurointervent Surg 8:1288-1293, 2016

18. Pierot L, Cognard C, Ricolfi F, Anxionnat R: Mid-term anatomic results after endovascular treatment of ruptured intracranial aneurysms with Guglielmi detachable coils and Matrix coils: analysis of the CLARITY series. AJNR Am J Neuroradiol 33:469-473, 2012

19. Piotin M, Spelle L, Mounayer C, Salles-Rezende MT, Giansante-Abud D, Vanzin-Santos R, et al: Intracranial aneurysms: treatment with bare platinum coils-aneurysm packing, complex coils, and angiographic recurrence. Radiology 243:500-508, 2007

20. Rouchaud A, Ramana C, Brinjikji W, Ding YH, Dai D, Gunderson T, et al: Wall apposition is a key factor for aneurysm occlusion after flow diversion: a histologic evaluation in 41 rabbits. AJNR Am J Neuroradiol 37:2087-2091, 2016

21. Shapiro M, Becske T, Nelson PK: Learning from failure: persistence of aneurysms following pipeline embolization. J Neurosurg 126:578-585, 2017

22. Shapiro M, Raz E, Becske T, Nelson PK: Variable porosity of the Pipeline Embolization Device in straight and curved vessels: a guide for optimal deployment strategy. AJNR Am J Neuroradiol 35:727-733, 2014

23. Spetzler RF, McDougall CG, Zabramski JM, Albuquerque FC, Hills NK, Russin JJ, et al: The Barrow Ruptured Aneurysm Trial: 6-year results. J Neurosurg 123:609-617, 2015

24. Szikora I, Berentei Z, Kulcsar Z, Marosfoi M, Vajda ZS, Lee $\mathrm{W}$, et al: Treatment of intracranial aneurysms by functional reconstruction of the parent artery: the Budapest experience with the Pipeline Embolization Device. AJNR Am J Neuroradiol 31:1139-1147, 2010
25. Tsang ACO, Fung AMY, Tsang FCP, Leung GKK, Lee R, Lui WM: Failure of flow diverter treatment of intracranial aneurysms related to the fetal-type posterior communicating artery. Neurointervention 10:60-66, 2015

26. Walcott BP, Stapleton CJ, Choudhri O, Patel AB: Flow diversion for the treatment of intracranial aneurysms. JAMA Neurol 73:1002-1008, 2016

\section{Disclosures}

The authors report no conflict of interest concerning the materials or methods used in this study or the findings specified in this paper.

\section{Author Contributions}

Conception and design: Trivelato, de Castro-Afonso, Abud. Acquisition of data: Trivelato, Rezende, Ulhôa, de Castro-Afonso, Nakiri. Analysis and interpretation of data: Trivelato, Rezende, Ulhôa, de Castro-Afonso, Abud. Drafting the article: Trivelato, Nakiri. Critically revising the article: Rezende, Abud. Reviewed submitted version of manuscript: all authors. Approved the final version of the manuscript on behalf of all authors: Trivelato. Study supervision: Abud.

\section{Correspondence}

Felipe Padovani Trivelato: Felício Rocho Hospital, Belo Horizonte, Minas Gerais, Brazil. felipepadovani@yahoo.com.br. 